\title{
Remote Working Challenges and Opportunities during Covid-19 Pandemic
}

\author{
KDV PRASAD \\ Institute of Industrial \& Human Resources Development (IIHRD), \\ Financial City, Gachibowli, Hyderabad, India.

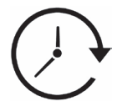

Article History

published by: 25 June 2021

Remote working or working from home is now buzz word across the globe as the Covid-19 pandemic changed the working topography enormously. In Remote work, where the staff or professional works beyond the traditional office settings, not necessary from a particular location. Several organizations across the globe irrespective of the type of organizations asked their employees to work from home wherever possible. Lockdowns were imposed in several counties which significantly affected the economies. The organizations allowed the employees more flexibility to work from home and have their schedules. The organizations are flexible even to modify the policies and procedures to get adjusted to this new environment. Eventually, the working class also adjusted to the Covid-19 pandemic environment and tried their best to deliver their respective outputs to meet the objectives of an organization balancing his/her requirements. It was reported that there remote working yielded much more productivity saving the commuting time as the employee have reasonable control and plan their activities in such a way that employee's personal and professional life existed peacefully, where he/she can work in full potential and personal satisfaction

\section{Challenges}

Organizational

To retain the best available talent and maintain low attrition rate is an important challenge for most of the organization. Managing attrition is also important to address the needs of internal and external stakeholders. The main challenge is re-skilling or up-skilling of the available staff on war-foot in minimum time, else employee may become to the exercise of trimming the groups. The lack of communication in the organization - lack of communication between peer-subordinate, stakeholders results in delayed decision making and project overruns. The organization should have all the necessary gadgets make available for

CONTACT KDV Prasad ${ }_{\text {k.d.prasad@cgiar.org }} \boldsymbol{9}$ Institute of Industrial \& Human Resources Development (IIHRD), Financial City, Gachibowli, Hyderabad, India.

\section{(c) (i)}

(C) 2021 The Author(s). Published by Enviro Research Publishers.

This is an $\partial$ Open Access article licensed under a Creative Commons license: Attribution 4.0 International (CC-BY).

Doi: http://dx.doi.org/10.12944/JBSFM.02.01.01 
better communication.In several organizations staff work in teams cohesively to fulfill the project goals. In certain projects, the team member's activities run parallel, however, in certain cases a member's activity needs to be completed to carry out the next activity. There is some risk involved in this arrangement during remote working which needs to be addressed. Workplace isolation is another important factor thataffects the employee's psychological well-being. The employee will miss the fun during breakout, tea and lunchtimes in the workplace. This significantly affects the employee's well-being because of boredom and missing the interaction with colleagues in the workplace. The daily interaction of staff with the peer, with the team, adherence to the policies, and organizational climate also affect the remote working.

\section{Individual}

At the individual level the employees need to handle family distraction, keeping good heal habits, role overload, role conflict i.e. which role e/she should be given priority as father/mother/wife/brother and sister. An individual should possess enough acumen to priorities his/her work, working with minimal supervision, handling team pressures, and should be able to withstand the situation should satisfy him/herself.

\section{External}

Adjusting to the different timing zones, lockdown restrictions, family fulfillment, communication with the external stakeholders and interruptions are some of the external challenges.

\section{Opportunities}

On the opportunities side an employee has the advantage of social and family support, flexible working hours, minimal supervision, absence of workplace politics and workplace pressures, and absence of communication. However, the employee needs to invest some resources for remote working on the internet and other technologies.

\section{Psychological Well-Being}

Several studies reported low psychological well-being of remote working employees due to a lack of positive relations, autonomy, and personal growth. Workplace isolation is affecting employee well-being.

\section{Conclusion}

The remote working concept will continue and stay for some more years. An employee needs to adjust to this remote working and the beauty of remote work is the fact that an employee can choose to work in a way that makes work-life balance perfect. By finding ways and means to accomplish perfect communication using the latest communication technologies. Several organizations have developed virtual recruitment practices, virtual meetings etc. using above mentioned communication tools. There were several studies reported huge savings for the companies as the employee are working remotely so the cost of infrastructure, electricity, commuting costs, and other indirect costs are saved. Increase in productivity, work-life balance, avoiding the risk of accidents and infection as the employee is not commuting daily to the office. An employee also could pursue his/her long-standing hobbies, professional pursuits etc., which could not be fulfilled due to time constraints or due to lack of freedom at the workplace to pursue them. Remote employees are less stressed compared to in-office counterparts with decreased absenteeism and better health and wellness.

\section{References}

1. Anderson, A. J., Kaplan, S. A., \& Vega, R. P. (2015). The impact of telework on emotional experience: When, and for whom, does telework improve daily affective well-being?. European Journal of Work and Organizational Psychology, 24(6), 882-897.

2. Felstead, A., \&Henseke, G. (2017). Assessing the growth of remote working and its consequences for effort, well-being and work-life balance. New Technology, Work and Employment, 32(3), 195-212.

3. Hickman, A. (2019). Workplace Isolation Occurring in Remote Workers. Doctoral Dissertation. Walden 
University.

4. Is Working Remotely Effective? Gallup Research Says Yes. Gallup Workplace. https://www.gallup.com/ workplace/283985/working-remotely-effective-gallup-researchsays-yes.aspx.

5. Kristen Senz. (2019). How Companies Benefit When Employees Work Remotely. Research and Ideas. Blog. https://hbswk.hbs.edu/item/how-companies-benefit-when-employeeswork-remotely.

6. Melanie Pinola. 2020. The 7 biggest remote work challenges (and how to overcome them). https:// zapier.com/blog/remote-work-challenges/.

7. Prasad, KDV., Rao, M., Vaidya, D. R., \& Muralidhar, B. (2020). Organizational climate, opportunities, challenges and psychological wellbeing of the remote working employees during COVID-19 pandemic: a general linear model approach with reference to information technology industry in hyderabad. International Journal of Advanced Research in Engineering and Technology (IJARET), 11(4):372-389

8. Remote working and its effects. Royal Society for Public Health in the UK, (2014), PGi

9. What is Remote work? (2020). https://remoteyear.com/blog/what-is-remote-work. 